\title{
First Case of Gyrate Atrophy with Hyperornithinemia in Cuba Di- agnosed by Ornithine Levels and Ophthalmological Evaluation
}

\author{
Contreras Roura Jiovanna ${ }^{1 *}$, Robaina Zoe ${ }^{1}$, Camayd Viera Ivette ${ }^{1}$, González-Gómez JC', \\ Pérez García $E^{2}$, Martínez-Rey Laritza ${ }^{1}$ and Padrón Aurelio David ${ }^{1}$
}

${ }^{1}$ HPLC Laboratory and Amino Acid Analysis, Department of Biochemical, National Center of Medical Genetics, La Habana, Cuba ${ }^{2}$ Department of Neuro-ophthalmology, ICO, Ramón Pando Ferrer, La Habana, Cuba

*Corresponding author: Jiovanna Contreras-Roura, HPLC Laboratory and Amino Acid Analysis, Department of Biochemical, Genetics National Center of Medical Genetics, La Habana, 146 Street, No.3102, 31 av. Cubanacán, Playa, CEP, 11300, Cuba, Tel: 5372089991,E-mail: jcontreras@infomed.sld.cu

\begin{abstract}
Gyrate atrophy of the fundus is a rare autosomal recessive disease characterized by deficiency of ornithine- $\delta$-aminotransferase. Ornithine- $\delta$-aminotransferase deficiency causes hyperornithinemia which results in progressive chorioretinal atrophy. Plasma levels of ornithine are elevated. Based on these observations, we describe the diagnosis of a patient with gyrate atrophy of the choroid and retina. This is the first report of Gyrate atrophy in Cuba, diagnosed by ornithine levels in blood and the ophthalmologist assessment.
\end{abstract}

\section{Keywords}

Gyrate atrophy, Hyperornithinemia, Electroretinogram, Retinal degeneration, Choroid, Pyridoxine

\section{Introduction}

Gyrate atrophy (GA) of the choroid and retina (GACR) is an extremely rare inherited retinal dystrophy. The disease is an autosomic recessive disorder, caused by mutations in the ornithine aminotransferase gene (OAT), which is localized on chromosome 10q26 [1-4].

The gene is expressed in the neuroretina and in the retinal pigment epithelium (RPE) [5-7] and encodes for the mitochondrial and pyridoxal phosphate-dependent enzyme ornithine aminotransferase, which is necessary for the conversion of ornithine into glutamate and proline [8]. Consequently, OAT gene mutations result in hyperornithinemia, typically with a 10-20-fold elevation of plasma ornithine levels [9-12].

Hyperornithinemia and ornithinuria were not recognized as the biochemical counterparts of this disorder until the report of Simell and Takkin, in 1973, 85 years after the initial ophthalmologic description [13]. Several studies suggest that an arginine-restricted diet [14-25] or a low-protein diet [22-24] may slow the progression of chorioretinal lesions and visual loss in gyrate atrophy. Most patients seem not to be responsive to pyridoxine; however, a few studies report of pyridoxine-responsive patients presenting with a reduction of ornithine level after pyridoxine substitution [22-24].

The highest incidence has been described in Finland, where affects approximately 1 in 50,000 individuals. About 200 cases with biochemically confirmed GA have been reported in the literature (http://omim.org/entry/258870) [13].

The first symptoms of GACR patients are night blindness and constriction of the visual field, caused by sharply demarked round areas of chorioretinal atrophy in the periphery, which increase and coalesce over years and spread toward the macula resulting in visual loss $[26,27]$ Additionally, myopia and early posterior subcapsular cataract are common in gyrate atrophy [28]. A further pathomorphological characteristic is cystoid macula edema, which can be detected in optical coherence tomography (OCT) scans $[29,30]$. 
The aim of this work is to describe the diagnosis of a first Cuban patient with gyrate atrophy of the choroid and retina through ophthalmological tests and biochemical results of the first case of gyrate atrophy with hyperornithinemia in Cuba.

\section{Methods}

\section{Ophthalmological evaluation}

Mixed 6-year-old female patient was referred to consultation because her teacher noted near-sightedness on school. The case was evaluated by the ophthalmology and genetics service. The patient was examined in 2014 and 2015 in the Department of neuro-ophthalmology by the "Ramon Pando Ferrer" Cuban Institute of Ophthalmology. Clinical genetics history was made, and plasma ornithine quantification was requested. Her family history was unremarkable. Clinical examinations and blood collection for serum ornithine level were conducted after obtaining informed consent. The research adhered to the tenets of the Declaration of Helsinki. The patient underwent a complete ophthalmological examination including best-corrected visual acuity (decimal fraction), slit-lamp biomicroscopy, and funduscopy. Kinetic visual field testing was performed with Goldmann, perimetry. OCT and FAF imaging were carried out using the Spectralis Heidelberg Retina Angiograph (Heidelberg Engineering, Heidelberg, Germany). For FAF, argon laser light ( $488 \mathrm{~nm}$ ) was used to excite autofluorescence in the RPE, with a wide band-pass filter and a cutoff at $500 \mathrm{~nm}$ inserted in front of the detector. A 30_field of view was used to obtain mean images as provided during the imaging process.

The full-field electroretinogram (ERG) was recorded according to the International Society for Clinical Electrophysiology of Vision (ISCEV) standards [30,31] ERG recordings were made with a Nicolet Spirit and Ganzfeld bowl (Nicolet, Madison, USA) using DTL fiber electrodes (Unimed Electrode Supplies Ltd, England). Following 30 min of dark adaptation, four stimuli of increasing intensity were used to obtain rod responses and the standard combined rod-cone response (maximum light intensity: $1.5 \mathrm{~cd} \mathrm{~s} / \mathrm{m}^{2}$ ).

After 10 min of light adaptation to a white background light of $25 \mathrm{~cd} / \mathrm{m}^{2}$, single-flash cone and $30-\mathrm{Hz}$ flicker responses were recorded using the maximum stimulus intensity.

\section{Biochemical evaluation}

Plasma amino acids quantification: A Prominence HPLC system (Shimadzu, Japan) is used for biochemical diagnosis of GACR. Gradient reverse-phase HPLC is used for quantification of amino acids in plasma with pre-column derivatization with phenyl isothiocyanate (PITC) and ultraviolet detection ( $254 \mathrm{~nm}$ ). The LC Chromatography Data System Solutions program (Shimadzu, Japan) was used for data acquisition and processing. All determinations were performed at $30{ }^{\circ} \mathrm{C}$, using a Shim-pack ODS-GHRS $4 \mathrm{~mm} \times 1 \mathrm{~cm}$ pre-column and Shim-pack CLC-
ODS $25 \mathrm{~cm}, 5 \mu \mathrm{m}$ column (Shimadzu, Japan), a flow of 1 $\mathrm{mL} / \mathrm{min}$ and injection volume of $50 \mu \mathrm{L}$. Sample quantification relies on ornithine calibration curves prepared in plasma with concentration range of 100-800 $\mu \mathrm{M}$.

Organic acid profile in urine: Samples were processed as described by Camayd, et al. [32] using fresh random urine samples ( $2 \mathrm{~mL}$ or more). Briefly: Volumes corresponding to $0.25 \mathrm{mg}$ of creatinine were alkalinized to $\mathrm{pH}=14$ and treated with $500 \mu \mathrm{L}$ of hydroxylamine hydrochloride. The resulting mixture was acidified to $\mathrm{pH}=1$, saturated with approximately $500 \mathrm{mg}$ of sodium chloride and extracted twice with ethyl acetate. Finally, the resulting organic phases were pooled, evaporated under Nitrogen at $50{ }^{\circ} \mathrm{C}$ and derivatized with $100 \mu \mathrm{L}$ of $\mathrm{N}$-Methyl-N-(trimethylsilyl)trifluoroacetamide. One microliter of each derivatized sample was injected. A GC-MS Shimadzu QP2010 equipped with an AOC-20i autoinjector (Tokyo, Japan) was used to carry out the analysis. Compounds were separated as trimethylsilyl derivatives using a DB-5 MS capillary column $(30 \mathrm{~m} \times$ $0.25 \mathrm{~mm}$ I.D., cross-linked 5\% phenyl-methyl silicone, $0.25 \mu \mathrm{m}$ film thickness). Chromatographic conditions were as follows: Helium was used as carrier gas (flowrate of $1 \mathrm{~mL} / \mathrm{min}$ ), and split ratio was $1: 10$. The $\mathrm{GC}$ oven temperature was set from $80^{\circ} \mathrm{C}$ ( $5 \mathrm{~min}$ hold) to $300^{\circ} \mathrm{C}$ at a rate of $7^{\circ} \mathrm{C} / \mathrm{min}(5 \mathrm{~min}$ hold). The interface and injector temperatures were $280^{\circ} \mathrm{C}$ and $250{ }^{\circ} \mathrm{C}$, respectively, electron impact ionization applied was $70 \mathrm{eV}$. The mass spectrometer was programmed from a mass/charge ratio $(\mathrm{m} / \mathrm{z}) 10-650$ at the rate of $0.6 \mathrm{~Hz}$.

Biochemical follow-up: To define pyridoxine responsiveness, the patient was treated with pyridoxine $(500 \mathrm{mg} /$ day) immediately after diagnosis for six months, and a follow-up sample was requested for amino acid analysis. Finally, a low-protein diet-supplemented with pyridoxine $(500 \mathrm{mg} /$ day)-was started and plasma amino acid levels were quantified after a six-month period of treatment and one year after diagnosis [22-24].

\section{Results}

\section{Ophthalmological analysis}

Mixed 6-year-old was referred to consultation because her teacher noted near-sightedness on school. The general ophthalmologist exam noted changes on fundus examination, suggestive of retinal dystrophy. Her refractive error measured $-6.00-1.00 \times 180^{\circ}$ for the right eye and $-6.50-1.00 \times 35^{\circ}$ for the left eye. Her best corrected visual acuity was $20 / 20$ in the right eye and 20/25 in the left eye. Color vision was within normal limits in both eyes. Pneumotonometry revealed normal intraocular pressure (IOP) in each eye. Pupil reflex were normal. Anterior segment examinations were quiet bilaterally. Fundus examination revealed bilateral sharply demarcated areas of choroid and retinal atrophy in gyrate shape and involving the midperiphery, the posterior pole was spared of these lesions with the mac- 

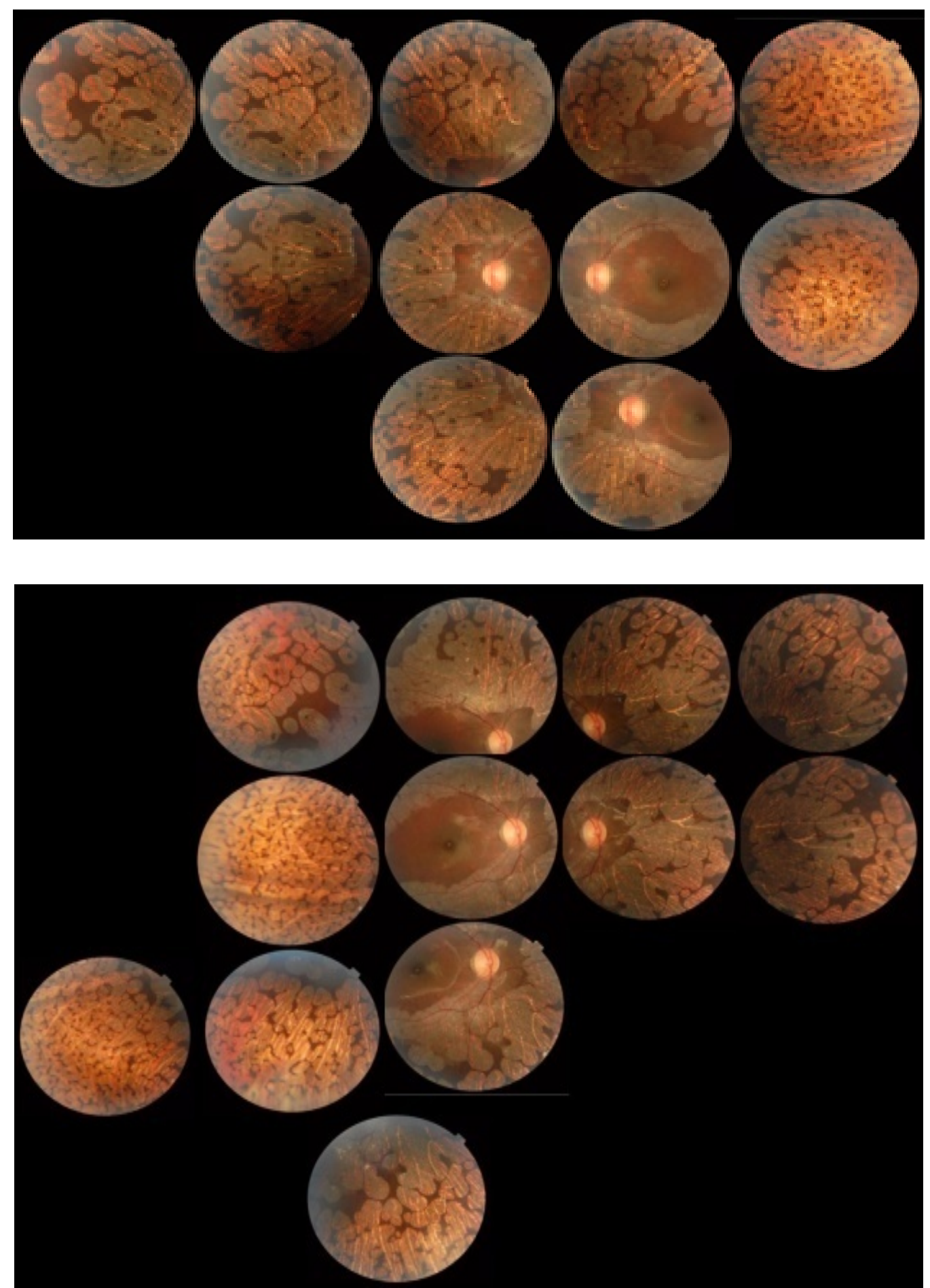

Figure 1: Fundus Photography showing bilateral sharply demarcated areas of choroid and retinal atrophy in gyrate shape involving the midperiphery, posterior poles were spared of these lesions.

ula not affected. (Figure 1) Disclosed cystoid macular edema was evident in both eyes on optical coherence tomography (Figure 2). Electroretinography (performed to International Society for Clinical Electrophysiology of Vision standards) showed virtually abolished responses in scotopic conditions. 32 Dynamic Octopus perimetry demonstrated visual field constriction in each eye. (Figure 3) Electromyography was normal.

\section{Biochemical evaluation}

The patient was referred to the genetics service and clinical genetics history is made. Family history that proves to be the only case in the family, no positive perinatal history and there is a history of language disorders and learning. Amino acid analysis revealed a high plasma ornithine level demonstrating deficiency of the activity of OAT (Table 1). Plasma ammonia, as well as orotic acid (GC-MS) and homocitrulline were not elevated. She was treated with pyridoxine $(500 \mathrm{mg} /$ day $)$ and low protein diet $(0.8 \mathrm{~g} / \mathrm{kg} /$ day) but not significant reduction plasma ornithine level was obtained until now and without effect in terms visual acuity after 12 months of follow-up (Table 1). The clinical diagnosis of the patient was consistent with ornithine- $\delta$-aminotransferase 
Right eye

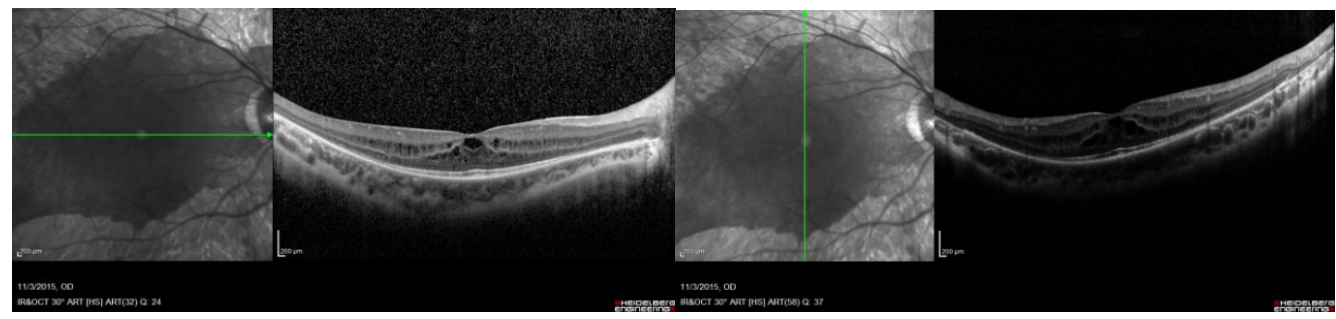

Left eye
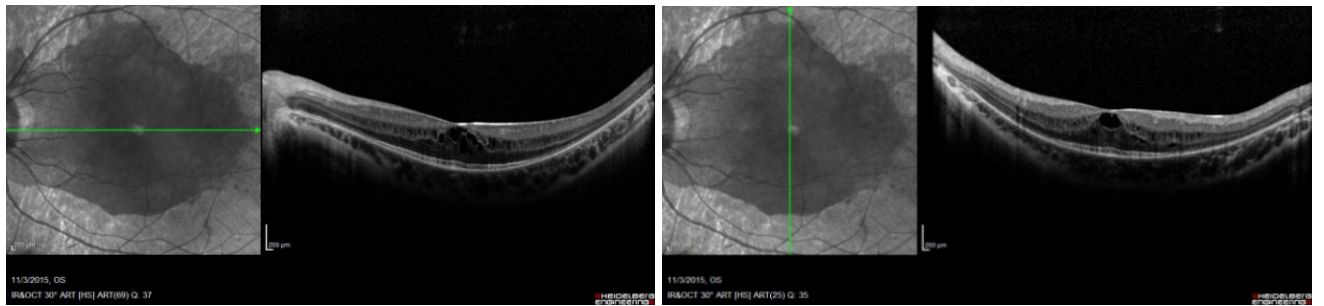

Figure 2: Optical coherence tomography showing thickened macula due to cystoid macular edema evident in both eyes.

Table 1: Plasma amino acid levels at the diagnosis moment, before treatment (sample I) with Pyridoxine treatment, six months after the diagnosis; (sample II) and with pyridoxine treatment and low protein diet; one year after the diagnosis (sample III).

\begin{tabular}{|c|c|c|c|c|c|c|}
\hline Amino acid & Sample I & Samnlo II & Samnlo II & Control & Control $^{b}$ & $\mathbf{G A}^{\mathbf{b}}$ \\
\hline $\mathrm{C}(\boldsymbol{\mu} \mathrm{M})$ & sample I & sample II & Sample III & $(2-18 \text { years })^{a}$ & $(n=22)$ & $(n=4)$ \\
\hline Ornithine & 975 & 1078 & 1692 & $10-163$ & $71-81$ & $979-1023$ \\
\hline Arginine & 522 & 66 & 143 & $10-140$ & $95-107$ & $120-136$ \\
\hline Lysine & 274 & 238 & 174 & $48-284$ & $198-216$ & $112-130$ \\
\hline Histidine & 334 & 224 & 152 & $41-125$ & $80-88$ & 94-104 \\
\hline Valine & 598 & 276 & 303 & $74-321$ & $228-246$ & $94-214$ \\
\hline Isoleucine & 76 & 93 & 97 & $22-107$ & $65-73$ & $53-57$ \\
\hline Leucine & 305 & 239 & 142 & $49-216$ & $130-142$ & $103-109$ \\
\hline
\end{tabular}

${ }^{\mathrm{a}}$ From [41]; ${ }^{\mathrm{b}}$ From [42].

(OAT) deficiency, unresponsive to pyridoxine treatment variant, and gyrate atrophy of the choroid and retina.

\section{Discussion}

The gyrate atrophy of the retina and choroid usually affects individual white. There is only one case described a family African belonging to the black racial group [33]. Also affect both sexes, with onset in childhood. Patients with GA initially complain of decreasing visual acuity and loss of night vision [34]. Eventually, loss of central vision occurs in the fourth to fifth decades [27]. The fundus in patients with GA exhibits circular, well demarcated chorioretinal atrophy with hyperpigmented margins in the midperiphery [35]. Patients with GA may also have myopia and posterior subcapsular cataracts [36]. Usually the fundus finding of scalloped chorioretinal atrophy in the midperiphery is sufficiently characteristic to determine GA. Advanced choroideremia with generalized atrophy of the retinal pigment epithelium and choriocapillaris may be confused. Choroideremia is an X-linked disorder and the macula may be involved earlier than GA. The other differential diagnosis includes diffuse choriocapillaris atrophy, generalized choroidal dystrophy and central areolar choroidal dystrophy. Plasma ornithine levels help to confirm GA, is a genetic disorder caused by OAT deficiency that results in markedly elevated lev- els of ornithine in plasma and other body fluids [37]. The exact mechanism of chorioretinal atrophy due to hyperornithinemia is not known, although a low-arginine diet and Pyridoxine supplementation may decrease plasma ornithine levels and reduce the progression of GA [9]. However, the long-term effects of this treatment approach have not been completely evaluated. More than 60 different mutations in the OAT gene locus have been identified [38-40].

Patients with GA generally present with decreased night vision and high myopia during their adolescence, and early diagnosis in these patients allows for early treatment. Indeed, OAT gene studies in children with a high degree of myopia, especially in cases in which there is a complaint of nyctalopia, would be helpful for early identification. To the best of our knowledge, this is the first report of GA in the Cuban population diagnosed by ornithine levels in blood and treated with Pyridoxine dietary supplementation and low protein diet.

Two distinct entities are associated with significant increment in plasma ornithine concentration: Gyrate Atrophy of the choroid and retina (MIM 258870), and the Hyperornithinemia-hyperammonemia-homocitrullinuria (HHH) Syndrome (MIM 238970). In patients with gyrate atrophy, visual symptoms first appearance typically occurs 
A
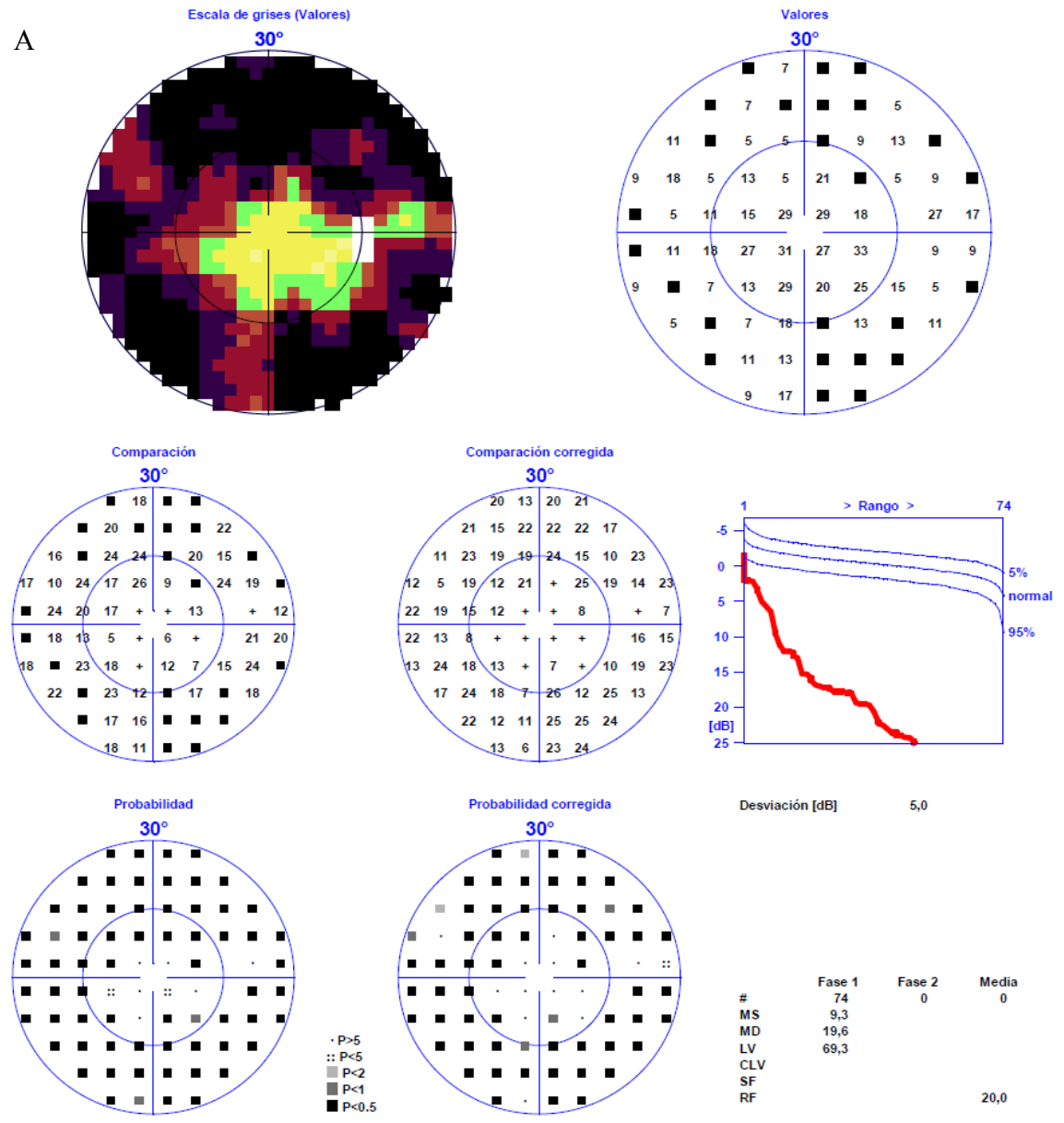

Desviación [dB] $\quad 5,0$

B
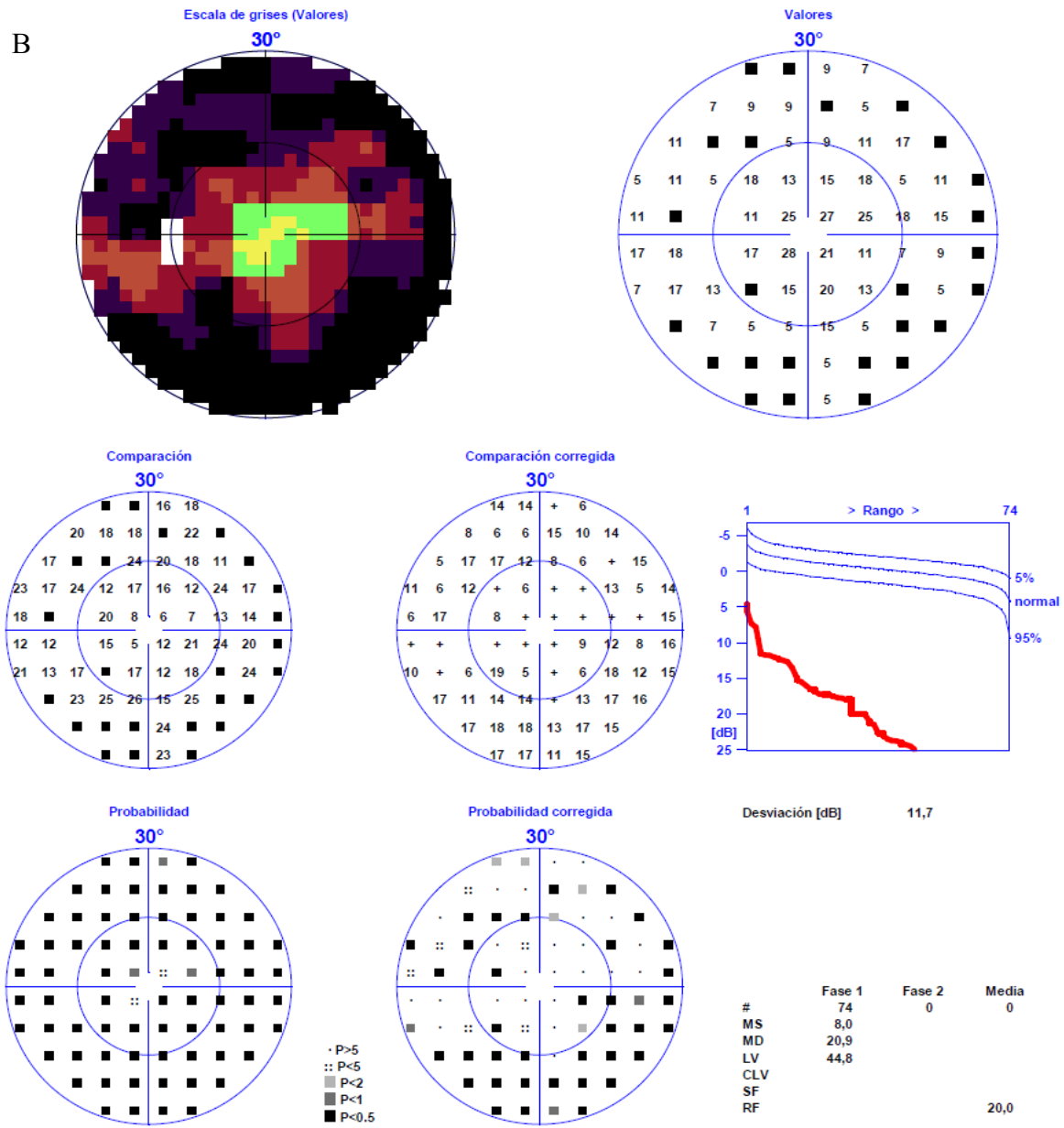

Desviación [dB] $\quad 11,7$

Figure 3: HAAG STREIT Octopus 101 (32 Dynamic) visual field testing A) Left eye and B) Right eye showing constricted fields. 
at late childhood and after the first few months of life, plasma ornithine concentration ranges from 400 to 1300 $\mu \mathrm{M}$ and plasma ammonium is not elevated. However, the $\mathrm{HHH}$ syndrome usually presents with plasma ornithine levels lower than in gyrate atrophy (200 to $1100 \mu \mathrm{M})$, while ammonium and glutamine plasma concentrations are increased, particularly after ingestion of a protein load. Urinary excretion of ornithine and its $\delta$-lactam are increased in both types of hyperornithinemia, while homocitrulline usually is not present in urine, is found only in the $\mathrm{HHH}$ syndrome. Urinary excretion of orotic acid also is incremented in individuals with $\mathrm{HHH}$ [13].

\section{Limitations}

Clinical and biochemical findings for this case suggest the diagnosis of AG; however, molecular studies could not be carried out to identify the underlying mutation.

\section{Conclusions}

The patient is the first case diagnosed in Cuba with AG associated with hyperornitinemia. It is a new challenge to perform the molecular study to identify our patients' mutations. The accessibility of genetic services will allow the identification of new cases.

\section{Acknowledgements}

We would like to acknowledge the assistance of Ophthalmologists from Neurophthalmology Department of ICO “Ramón Pando Ferrer”, La Habana. Cuba.

\section{Declaration of Interest}

The authors report no conflicts of interest. The authors alone are responsible for the content and writing of this article.

\section{Informed Consent}

All procedures followed were in accordance with the ethical standards of the responsible committee on human experimentation (institutional and national) and with the Helsinki Declaration of 1975, as revised in 2013. Informed consent was obtained from the guardians of the patient for being included in the study. In addition, the research protocol was reviewed and approved by the medical ethics committee of the National Center of Medical Genetics.

\section{Conflict of Interest}

The authors report no conflicts of interest. The authors alone are responsible for the content and writing of this article.

\section{References}

1. Mitchell GA, Looney JE, Brody LC, Steel G, Suchanek M, et al. (1988) Human ornithine-delta-aminotransferase. cDNA cloning and analysis of the structural gene. J Biol Chem 263: 14288-14295.

2. Ramesh V, Benoit LA, Crawford P, Harvey PT, Shows TB, et al. (1988) The ornithine aminotransferase (OAT) locus:
Analysis of RFLPs in gyrate atrophy. Am J Hum Genet 42: 365-372.

3. Wu J, Ramesh V, Kidd JR, Castiglione CM, Myers S, et al. (1988) The ornithine aminotransferase (OAT) locus is linked and distal to D10S20 on the long arm of chromosome 10. Cytogenet Cell Genet 48: 126-127.

4. Guevara Márquez YC, Vela Amieva $M$, Juárez Echenique JC, Ordáz Favila JC, Belmont Martínez L (2013) Manifestaciones oftalmológicas de los errores innatos del metabolismo. Acta Pediatr Mex 34: 212-224.

5. Rao GN, Cotlier E (1984) Ornithine delta-aminotransferase activity in retina and other tissues. Neurochem Res 9: 555562.

6. Ratzlaff K, Baich A (1987) Comparison of ornithine aminotransferase activities in the pigment epithelium and retina of vertebrates. Comp Biochem Physiol B 88: 35-37.

7. Bernstein SL, Wong P (1998) Regional expression of disease-related genes in human and monkey retina. Mol Vis 4: 24.

8. O'Donnell JJ, Sandman RP, Martin SR (1978) Gyrate atrophy of the retina: Inborn error of L-ornithin: 2-oxoacid aminotransferase. Science 200: 200-201.

9. Simell O, Takki K (1973) Raised plasma-ornithine and gyrate atrophy of the choroid and retina. Lancet 1: 1031-1033.

10. Takki K, Simell O (1974) Genetic aspects in gyrate atrophy of the choroid and retina with hyperornithinaemia. Br J Ophthalmol 58: 907-916.

11. Takki K (1974) Gyrate atrophy of the choroid and retina associated with hyperornithinaemia. $\mathrm{Br} \mathrm{J}$ Ophthalmol 58: 3-23.

12. Vannas Sulonen K, Sipila I, Vannas A, Simell O, Rapola J (1985) Gyrate atrophy of the choroid and retina. A five-year follow-up of creatine supplementation. Ophthalmology 92: 1719-1727.

13. Valle D, Simell O (2001) The Hyperornithinaemias. In: Scriver CR, Beaudet AL, Sly WS, Valle D, The metabolic and molecular bases of inherited disease. ( $8^{\text {th }}$ edn), McGraw-Hill, New York, USA, 1857-1895.

14. Kaiser Kupfer MI, de Monasterio FM, Valle D, Walser M, Brusilow S (1980) Gyrate atrophy of the choroid and retina: Improved visual function following reduction of plasma ornithine by diet. Science 210: 1128-1131.

15. Kaiser Kupfer MI, de Monasterio F, Valle D, Walser M, Brusilow S (1981) Visual results of a long-term trial of a low-arginine diet in gyrate atrophy of choroid and retina. Ophthalmology 88: 307-310.

16. Kaiser Kupfer MI, Caruso RC, Valle D (1991) Gyrate atrophy of the choroid and retina. Long-term reduction of ornithine slows retinal degeneration. Arch Ophthalmol 109: 1539-1548.

17. Kaiser Kupfer MI, Caruso RC, Valle D (2002) Gyrate atrophy of the choroid and retina: Further experience with longterm reduction of ornithine levels in children. Arch Ophthalmol 120: 146-153.

18. Kaiser Kupfer MI, Caruso RC, Valle D, Reed GF (2004) Use of an arginine-restricted diet to slow progression of visual loss in patients with gyrate atrophy. Arch Ophthalmol 122: $982-984$.

19. Valle D, Walser M, Brusilow SW, Kaiser Kupfer M (1980) Gyrate atrophy of the choroid and retina: Amino acid metabolism and correction of hyperornithinaemia with an argi- 
nine-deficient diet. J Clin Invest 65: 371-378.

20. Valle D, Walser M, Brusilow S, Kaiser Kupfer MI, Takki K (1981) Gyrate atrophy of the choroid and retina. Biochemical considerations and experience with an arginine-restricted diet. Ophthalmology 88: 325-330.

21. Weleber RG, Kennaway NG, Buist NR (1981) Gyrate atrophy of the choroid and retina. Approaches to therapy. Int Ophthalmol 4: 23-32.

22. Santinelli R, Costagliola C, Tolone C, D'Aloia A, D'Avanzo A, et al. (2004) Low protein diet and progression of retinal degeneration in gyrate atrophy of the choroid and retina: $A$ twenty-six-year followup. J Inherit Metab Dis 27: 187-196.

23. AC Sergio Rojas Juárez, Adriana Saucedo Castillo (2013) Retina y Vítreo. El Manual Moderno. ( $2^{\text {nd }}$ edn), Asociación Mexicana de Retina, México, 157-159.

24. Angel Gil Hernandez (2010) Tratado de Nutrición: Nutrición clínica. Nutrición clínica. ( $2^{\mathrm{a}}$ edn), Editorial, Médica Panamericana, 933-936.

25. Weleber RG (2006) Gyrate atrophy of the choroid and retina. In: Heckenlively JR, Arden GB, Principles and practice of clinical electrophysiology of vision. The MIT Press, Cambridge, UK, 705-715.

26. McCulloch C, Marliss EB (1975) Gyrate atrophy of the choroid and retina: Clinical, ophthalmologic, and biochemical considerations. Trans Am Ophthalmol Soc 73: 153-171.

27. Takki KK, Milton RC (1981) The natural history of gyrate atrophy of the choroid and retina. Ophthalmology 88: 292301.

28. Kaiser Kupfer M, Kuwabara T, Uga S, Takki K, Valle D (1983) Cataract in gyrate atrophy: Clinical and morphologic studies. Invest Ophthalmol Vis Sci 24: 432-436.

29. Oliveira TL, Andrade RE, Muccioli C, Sallum J, Belfort R $\mathrm{Jr}$ (2005) Cystoid macular edema in gyrate atrophy of the choroid and retina: A fluorescein angiography and optical coherence tomography evaluation. Am J Ophthalmol 140: 147-149.

30. Vasconcelos Santos DV, Magalhaes EP, Nehemy MB (2007) Macular edema associated with gyrate atrophy managed with intravitreal triamcinolone: A case report. Arq Bras Oftalmol 70: 858-861.
31. Marmor MF, Fulton AB, Holder GE, Miyake Y, Brigell M, et al. (2009) ISCEV Standard for full-field clinical electroretinography (2008 update). Doc Ophthalmol 118: 69-77.

32. Camayd-Viera I, Nuevas-Paz L, Concepción-Álvarez A (2015) Diagnóstico bioquímico de acidurias orgánicas en Cuba: Periodo 2008-2013. Acta Bioquím Clín Latinoam 49: 209-214.

33. Peltola KE, Nanto Salonen K, Heinonen OJ, Jaaskelainen S, Heinanen K, et al. (2001) Ophthalmologic heterogeneity in subjects with gyrate atrophy of choroid and retina harboring the L402P mutation of ornithine aminotransferase. Ophthalmology 108: 721-729.

34. Kaiser Kupfer MI, Valle D, Bron AJ (1980) Clinical and biochemical heterogeneity in gyrate atrophy. Am J Ophthalmol 89: 219-222.

35. Ramesh V, Shaffer MM, Allaire JM, Shih VE, Gusella JF (1986) Investigation of gyrate atrophy using a cDNA clone for human ornithine aminotransferase. DNA 5: 493-501.

36. Inana G, Totsuka S, Redmond M, Dougherty T, Nagle J, et al. (1986) Molecular cloning of human ornithine aminotransferase mRNA. Proc Natl Acad Sci U S A 83: 1203-1207.

37. Brody LC, Mitchell GA, Obie C, Michaud J, Steel G, et al. (1992) Ornithine delta-aminotransferase mutations in gyrate atrophy. Allelic heterogeneity and functional consequences. J Biol Chem 267: 3302-3307.

38. Weleber RG, Kennaway NG (1981) Clinical trial of vitamin $\mathrm{B} 6$ for gyrate atrophy of the choroid and retina. Ophthalmology 88: 316-324.

39. Raitta C, Carlson S, Vannas Sulonen K (1990) Gyrate atrophy of the choroid and retina: ERG of the neural retina and the pigment epithelium. $\mathrm{Br} \mathrm{J}$ Ophthalmol 74: 363-367.

40. Doimo M, Desbats MA, Baldoin MC, Lenzini E, Basso G, et al. (2013) Functional analysis of missense mutations of OAT, causing gyrate atrophy of choroid and retina. Human Mutat 34: 229-236.

41. (1991) Techniques in Diagnostic Human Biochemical Genetics: A Laboratory Manual. A John Wiley \& Sons, INC, New York, USA.

42. D Valle, M Walser, SW Bruisilotv, M Kaiser-Kupfer (1980) Gyrate Atrophy of the Choriod and Retina: Amino acid metabolism and correction of hyperornithinemia with an arginine-deficient diet. J Clin Invest 65: 371-378. 